\title{
Ekstrahepatik yerleşimli primer intraabdominal kist hidatiklere cerrahi yaklaşım
}

\section{Surgical approach to primary intraabdominal hydatid cysts with extrahepatic location}

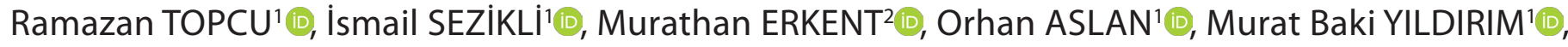 \\ Murat Bulut ÖZKAN'回 Doğukan DURAK'
}

${ }^{1}$ Hitit Üniversitesi Erol Olçok Eğitim ve Araştırma Hastanesi, Genel Cerrahi Anabilim Dalı, Çorum/TÜRKIYE ${ }^{2}$ Başkent Üniversitesi Tıp Fakültesi Genel Cerrahi Anabilim Dalı, Ankara/TÜRKIYE

\section{Öz}

Amaç: Kist hidatik ülkemiz için yaygın bir sağlık sorunu olarak önemini korumaktadır. En sık karaciğer ve akciğer yerleşimli olup karın içi diğer organların primer tutulumu oldukça nadirdir. Ekstrahepatik primer intraabdominal hidatik kist nedeniyle cerrahi tedavi ettiğimiz olguları literatür eşliğinde incelendik.

Gereç ve Yöntemler: Ekstrahepatik primer intraabdominal hidatik kist tanısyla opere edilen toplam 9 hastanın tıbbi kayıtları geriye dönük olarak incelendi.

Bulgular: Hastaların 6'sı kadın, 3'ü erkek olup yaş ortalamaları 49,6 (22-74) olarak saptandı. Polikliniğe basvurma şikayetleri; 3 'ünde mide ağrısı, $5^{\prime}$ inde şişkinlik, $1^{\prime}$ inde ise sarılık idi. Kist yerleșimi 5 olguda dalak, 3 olguda retroperitoneal, 1 olguda gastrokolik ligament olarak saptandı.Kist boyutu ortalama 9,5 (5-13) cm olarak hesaplandı. Hastaların 4'üne splenektomi, 1'ine laparoskopik splenektomi, 2'sine total perikistektomi ve 2'sine total perikistektomi+kolesistektomi yapıldı.Mortalite olmadı. Hastaların 2'sinde yara yerinde Hematom 1 'inde yara yeri enfeksiyonu gelişti.Ortalama hastanede yatıs 5,2 gün(4-8) idi. Taburculuk sonrası hastalara 6 ay andazol baslandı.Hastaların hepsi 6 ay sonra kontrole cagrıldı ve Usg ile kontrol edildi.Ortalama takip süresi 18,1 (6-43) ay idi. Takip sürelerinde herhangi nükse rastlanılmadı.

Sonuç: Echinococcus granulosus'un her organı tutabileceği unutulmamalıdır. Bu yüzden KC ve AC tutulumu olmasa bile tüm sistem tetkik edilmelidir. Batın içi kitlelerde özellikle endemik bölgelerde Ekstrahepatik primer intraabdominal hidatik kist akla getirilmelidir ve tedavide nüksü tamamen ortadan kaldıran total perikistektomi veya organ rezeksiyonu seçilecek tedavi yöntemdir.

Anahtar kelimeler: ekstrahepatik kist hidatik; total perikistektomi; nüks

Sorumlu Yazar*: Ramazan TOPCU, Hitit Üniversitesi Erol Olçok Eğitim ve Araştırma Hastanesi, Genel Cerrahi Anabilim Dalı, Çorum/TÜRKiYE E-posta: topcur58@gmail.com

ORCID: 0000-0001-6214-4868

Gönderim: 22/09/2020 kabul: 03/12/2020

Doi: $10.18663 /$ tjcl.798550 


\begin{abstract}
Aim: Hydatid cyst maintains its importance as a common health problem for our country. It is the most common liver, lung and primary involvement of other intra-abdominal organs is extremely rare. We reviewed the cases that we treated surgically for extrahepatic primary intraabdominal hydatid cyst in the light of the literature.
\end{abstract}

Methods: Medical records of 9 patients who were operated with extrahepatic primary intraabdominal hydatid cyst diagnosis were analyzed retrospectively.

Results: Six of the patients were female and 3 were male and their mean age was 49.6 (22-74). Complaints about applying to the outpatient clinic; There were stomach pain in 3, bloating in 5 and jaundice in 1. Cyst placement was determined as spleen in 5 cases, retroperitoneal in 3 cases and gastrocolic ligament in 1 case. The cyst size was calculated as an average of $9.5(5-13) \mathrm{cm}$. Splenectomy was performed in 4 patients, laparoscopic splenectomy in 1 patients, total pericystectomy in 2 patients, and total pericystectomy + cholecystectomy in 2 patients. No mortality occurred. Two of the patients developed hematoma at the wound site and 1 of them developed wound infection. The average hospital stay was 5.2 days (4-8).After discharge, the patients were started on 6 months of andazole. All of the patients were called for control after 6 months and checked with USG. The mean follow-up time was 18,1 (6-43) months. No recurrence was observed during follow-up.

Conclusion: It should be remembered that Echinococcus granulosus can hold every organ. Therefore, the entire system should be examined even if there is no involvement of liver and lung. Extrahepatic primary intraabdominal hydatid cyst should be considered in intra-abdominal masses, especially in endemic regions, and total pericystectomy or organ resection is the treatment method to be selected in the treatment that completely eliminates recurrence.

Keywords: extrahepatic cyst hydatid; total pericystectomy; recurrence

\section{Giriş}

Kist Hidatik tarım ve hayvancılıkla uğraşan insanlarda görülen, hayvanlardan insanlara geçen endemik paraziter bir hastalıktır. Birçok ülkede, insanların, sahip olduğu koyun, köpek gibi hayvanlarla yakın temasları parazitin hayat zincirinin kalıcı olmasını sağlar.[1] Bu helmintik hastalık dünya çapında izlenmekte olup Akdeniz havzası, Kuzey ve Doğu Afrika, Asya, Güney Amerika ve Avustralya ülkeleri gibi pek çok bölgede endemik olarak izlenmektedir.[2]

Kist Hidatik etkeni Sestod gurubunda yer alan bir parazit olup 4 alt grubu vardır ve en sık görülenleri Echinococcus granulosus ve Echinococcus multilocularis(alveolaris) dir.

Kist Hidatik tüm organları tutabilmekle birlikte en sık karaciğer (\%70) ve akciğeri (\% 15-20) tutar. Dalak tutulumu \% 0,9-\% 8 sıklıkla bildirilirken, izole dalak tutulumu çok nadirdir. Nadiren yumuşak dokular, kas-iskelet sistemi, kalp ve mesane gibi bölgelerde de görülebilir.[3] Parazit genellikle hematojen veya ince barsak lenfatikleri yoluyla yayılır; ancak batın içi yayılımı primer kistin spontan rüptürü ve parazitin intraperitoneal sIvı ile dolaşarak diğer organlara ekilmesi yoluyla da gerçekleşebilir.[4]

Genellikle asemptomatik olup, klinik ya bası bulgularına ya da kistin komplikasyonlarına baglı olarak ortaya çıkmaktadır.
Tanı için ultrasonografi (USG), bilgisayarlı tomografi (BT) ve manyetik rezonans inceleme (MRI) kullanılmaktadır.[5]

Kist hidatik (KH) tedavisinde temel prensipler; hastalığa sebep olan parazitin, ara konak formunun öldürülmesi ve/veya vücuttan uzaklaştırılması; kistin yol açabileceği komplikasyonların önlenmesi boşaltılması ve sorunsuz kapanmasının sağlanmasıdır. İdeal tedavi, hem hastalığın iyileştirilmesini tam olarak sağlamalı; hem de morbidite mortalitesi minimal olmalıdır.[6]

Ekstrahepatik primer intraabdominal hidatik kist nedeniyle cerrahi tedavi ettiğimiz olgular literatür eşliğinde incelendi ve yapılan cerrahinin nüks üzerine etkisine bakıldı.

\section{Gereç ve Yöntemler}

Mart 2017- Nisan 2020 yıllarına ait arşiv kayıtları esas alınarak, vakalar patoloji sonucu $\mathrm{KH}$ tanısı almış olgular olup toplam 56 hasta retrospektif olarak incelendi. Bunlardan extrahepatik primer KH 9 hasta çalışmaya dahil edildi. Olgular, yaş, cinsiyet ve lokalizasyonlarına göre sınıflandııılı. Tüm hastalarda tanı aşamasında klinik öykü, fizik muayene, laboratuvar testleri ve radyolojik yöntemlerden yararlanıldı. Ameliyat öncesinde hastalara akciğer grafisi, US ve BT yapıldı. İndirekt hemaglütinasyon (IHA) testinde $\geq 1 / 160$ serum titreleri pozitif olarak kabul edildi. Klinik öykülerinde daha önce hidatik kist nedeniyle te- 
davi görmedikleri ve ilk tanı olduğu öğrenildi. Hastaların tamamı elektif şartlarda opere edildi.Ameliyat sonrası hastalar 6 ay andozal kullandı ve kontrol USG ile takipleri yapıldı.

Tanı amacı ile laboratuvar testleri, immünolojik yöntemler ve radyolojik görüntüleme yöntemleri kullanıldı. Extrahepatik yerlesimli primer kist hidatik saptanan hastalara sistemik tarama yapıldı. Operasyon öncesi tüm hastalar hem USG hem de batın BT istendi ve tanıları konuldu.

Çalışma Helsinki Deklerasyonu kararlarına, hasta hakları yönetmeliğine ve etik kurallara uygun olarak planlandı. Çalışma öncesinde Ankara Numune Eğitim ve Araştırma Hastanesi etik kurulundan onay alındı.(Tarih:21.05,2020 ve Karar no:2020247 ) Hastalara aydınlatılmış onam belgesi imzalatıldı.

\section{İstatistiksel Analiz}

Verilerin analizi SPSS for Windows 11,5 paket programında yapıldı. Sürekli değişkenlerin dağılımının normale yakın olup olmadığı Shapiro Wilk testiyle araştırıldı. Tanımlayıcı istatistikler sürekli değişkenler için ortalama \pm standart sapma veya ortanca (minimum-maksimum) olarak kategorik değişkenler ise olgu sayısı ve (\%) şeklinde gösterildi.

\section{Bulgular}

Çalışmaya dahil edilen 9 hastanın 6'sı kadın, 3 'ü erkek olup yaş ortalamaları 49,6 (22-74) olarak bulundu. Polikliniğe başvurma şikayetleri; 3'ünde mide ağrısı, 5'inde şişkinlik, 1'inde ise sarılık idi. Kist yerleşimi BT'ye göre 5 olguda dalak (resim 1), 3 olguda retroperitoneal (resim 2), 1 olguda gastrokolik ligament (resim 3) yerleşimli olarak saptandı. Kist boyutu ortalama 9,5 (5-13) cm olarak hesaplandı.(şekil 1)

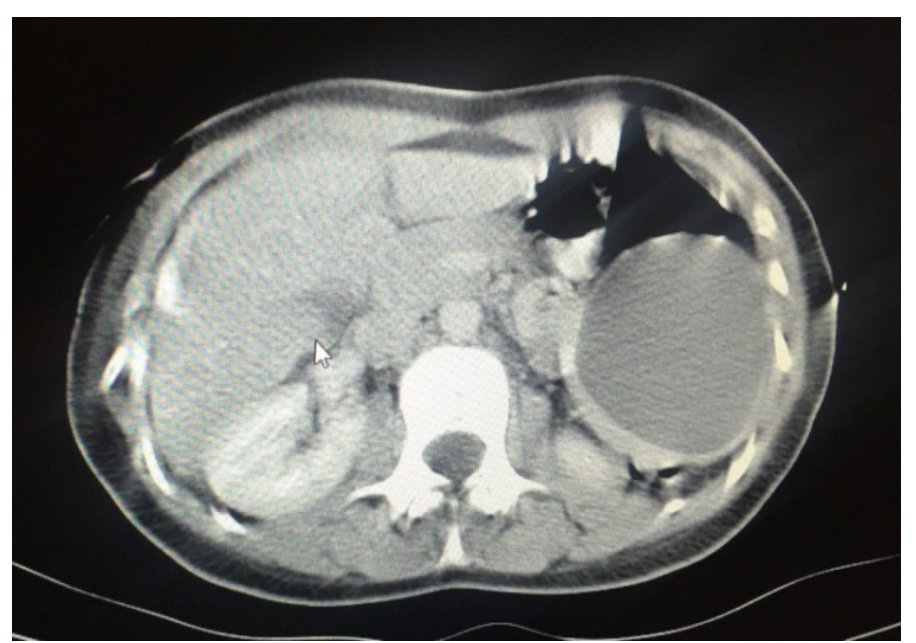

Resim -1 Dalak Kist Hidatik

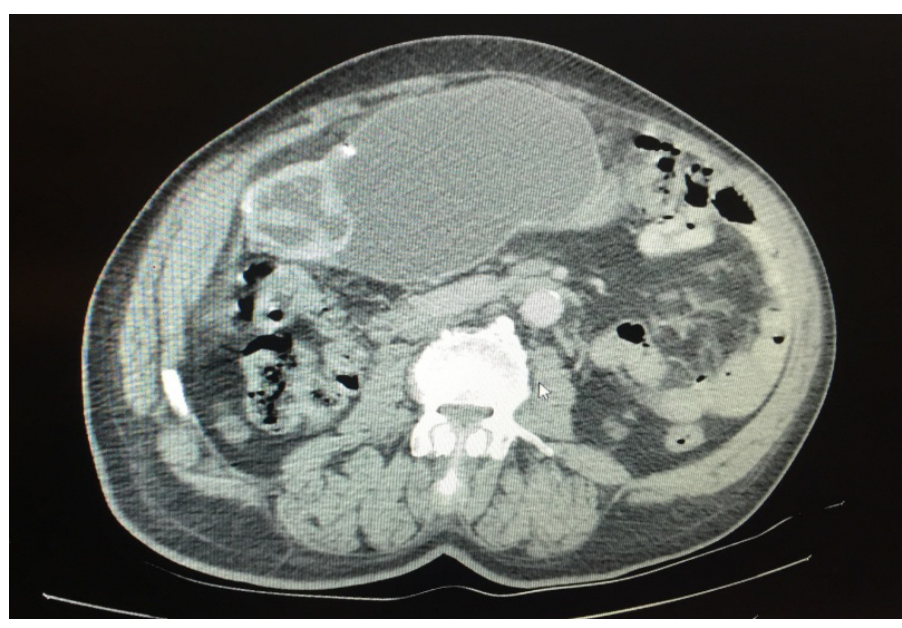

Resim-2 Gastrokolik ligament

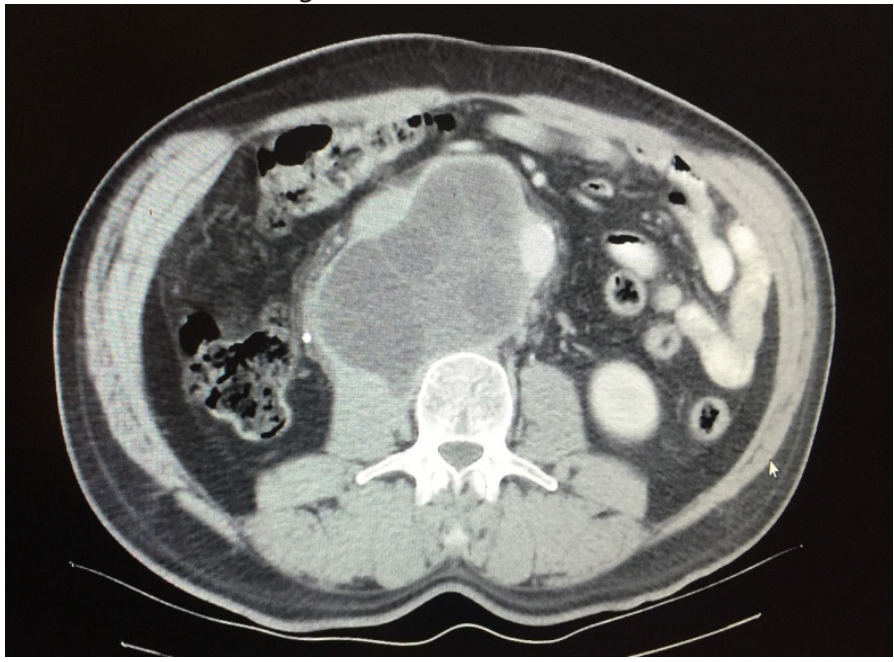

Resim -3 Retroduedonal

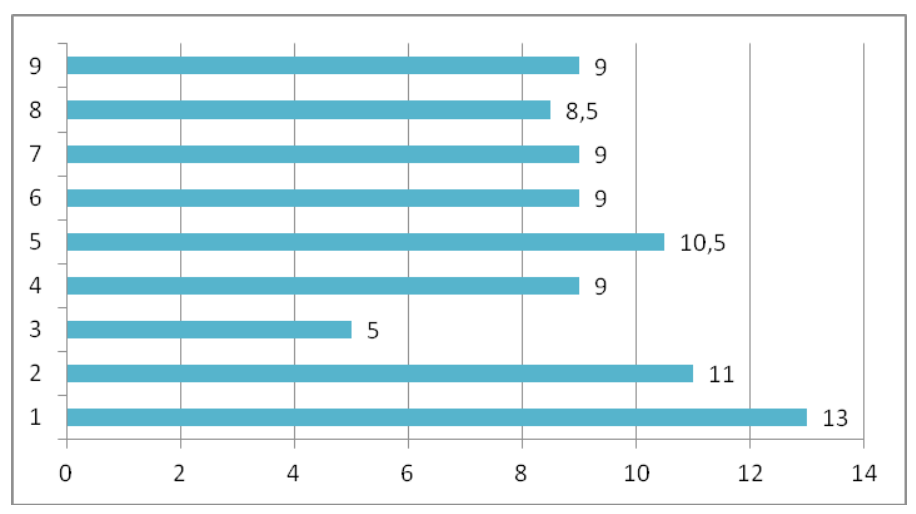

Sekil 1: Kist çapı (cm)

Tanı amacı ile laboratuvar testleri, immünolojik yöntemler ve radyolojik görüntüleme yöntemleri kullanıldı. Extrahepatik yerlesimli primer kist hidatik saptanan hastalara sistemik tarama yapıldı. Hastalar da İmmünolojik test olarak kullanılan IHA testinin $2(\% 22,2)$ hastada pozitif olduğu görüldü. Operasyon öncesi tüm hastalar hem USG hem de BT istendi ve tanıları konuldu. 
Hastalar genel anestezi altında, skolosidal ajan olarak \% 3 hipertonik solusyon kullanıldı.Hastaların 4'üne splenektomi , 1 'ine laparoskopik splenektomi, 2' sine total perikistektomi ve 2'sine total perikistektomi+kolesistektomi yapıldı (şekil-2). Mortalite olmadı. Hastaların 2'sinde yara yerinde Hematom 1 'inde yara yeri enfeksiyonu gelişti.Ortalama hastanede yatış 5,2 gün (4-8) idi.

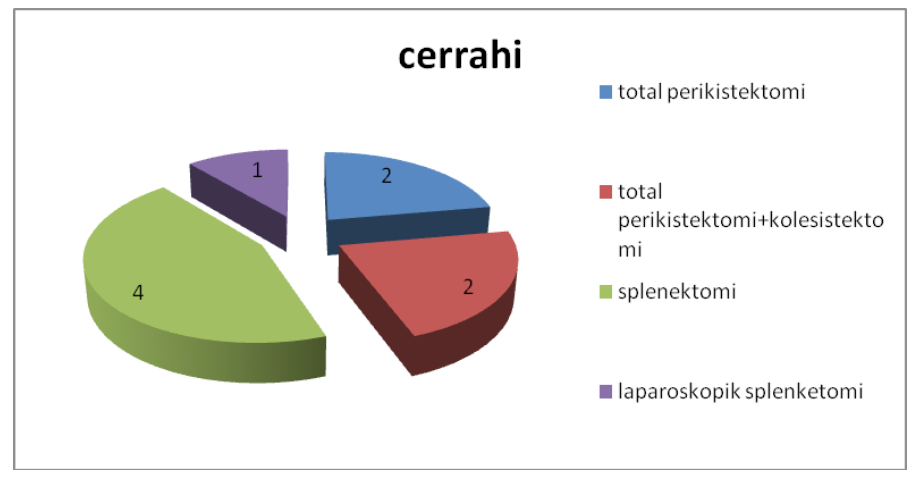

Sekil 2: cerrahi operasyon

Taburculuk sonrası hastalara $10 \mathrm{mg} / \mathrm{kg}$ dozunda 6 ay andazol başlandı. Hastaların hepsi 6 ay sonra kontrole çağrıldı ve USG ile kontrol edildi. Ortalama takip süresi 18,1 (6-43) ay idi.Takip sürelerinde herhangi nükse rastlanılmadı.

\section{Tartışma}

Ekinokokkus özellikle Avrupa, Asya, Akdeniz, Güney Amerika ve Afrika ülkelerinde endemik olarak görülmektedir.[7] Ülkemiz de KH açısından endemik bir bölge olarak değerlendirilmektedir.Türk toplumunda KH görülme sıklığı 1/2000 olarak bildirilmiştir.[8] Hidatik kist halen endemik bölgelerde yaygın olarak görülmektedir. Çoğunlukla karaciğer (\%70) ve akciğerde (\%20) yer almaktadır.[9,10] Ancak diğer organları da tutabilir. Ekstrahepatik intrabdominal hidatik kist tutulumu primer ya da sekonder olabilir. Primer ekstrahepatik intraabdominal hidatik kist oldukça nadirdir. Literatürde dalakta \%2,2, pankreasta $\% 1,1$, periton, pelvis ve mezokolonda $\% 2,2$, safra kesesinde $\% 0,6$ ve sürrenal bezde $\% 0,6$ olarak bildirilmiştir.[11] Bu çalışmada tüm hastaların 9'unun $(\% 6,1)$ primer ekstrahepatik intraabdominal hidatik kist olduğu saptandı. Bu hastaların da 5'inde dalak, 3'ünde retroperiton, bir olguyla da gastrokolik ligament içinde saptandı.

Dalak, üçüncü sıklıkta tutulan organ olmasına rağmen, endemik bölgelerde bile az görülen $(\% 2,5-5,8)$ bir durumdur. Dalak yerleşimli $\mathrm{KH}^{\prime}$ lerde, sistemik inceleme yapılmalı ve diğer organlarda bir tutulum olup olmadığı araştırılmalıdır.[12] Hasta- lık tablosu çoğunlukla sessiz olmasına rağmen, kistin enfekte olması, karın boşluğuna rüptür, gastrointestinal sisteme fistülizasyon ya da perforasyon gibi komplikasyonlar gelişebilmektedir .Bu çalışmada, izole dalak tutulumu; 5 vaka da saptandı ve tüm hastalara batın BT ve USG yapıldı.

Gastrokolik ligamentteki KH, oldukça nadir görüldüğü bölgelerdendir ve genellikle diğer organ tutulumuna ikincil olarak veya cerrahi sonrası görülür.[13] Kulaçoğlu ve ark. tarafından yapılan çalışma 3 vakada gastrokolik ligamentte KH saptanmıstır.[14] Bu çalışmada mide ağrısı ile gelen hastada yapılan BT de kist hidatik olduğu saptandı ve total perikistektomi uygulandı. Tüm tetkiklerde başka sistemlerde de kist hidatik olmadığı görüldü. Çok nadir görülen gastrokolik kist hidatik olarak tanımlandı.

Litaratürde retroperitoneal paraduedonal kist hidatikler hakkında çok az bilgi mevcut olup az görülmesine rağmen literatürde bildirilen toplam 4 vaka olup bu çalışmada 3 vakada olup 2 tanesine kolesistektomi+total perikistektomi birine de total perikistektomi yapıldı.

Klinik bulgular genelde asemptomatik olup semptomlar tutulan organlara, kistin büyüklüğüne ve organdaki yerleşimine, genişleyen kist ile kiste komşu organ yapıları arasındaki ilişkiye, kistin rüptürü sonucunda gelişen komplikasyonlara bağlıdır. $[15,16]$ Bu çalısmada; karında şiskinlik hissi olan 5 olgu, 3 hastada mide ağrısı ve 1 hastada basıya bağlı sarılık yakınması vardı.

IHA testi sıklıkla tercih edilmekte olup, duyarlılığı \%65-96.8 ve özgüllüğü \%90-100 dür.[17] USG ve BT tanıda oldukça yardımCı modalitelerdendir. US'nin tanısal duyarlılığı \%93-98, BT'nin ise \%97'dir.[18] Ekstrahepatik intraabdominal yerleşimli hidatik kist olgularında da genellikle USG ve batın BT yapılmaktadır.[19] Tanıda ilk önce, ucuz ve kolay uygulanabilir bir yöntem olan US tercih edilmelidir. Ancak ekstrahepatik karın içi hidatik kist olguları nadir görüldüğünden genelde tanıları BT ile konulmaktadır. Çalısmada preoperetif tüm hastalara hem USG hem de batın BT yapıldı.

Tedavi yöntemleri cerrahi, medikal ve perkütan aspirasyon injeksiyon reaspirasyon (PAIR) olmak üzere üç başlık altında incelenebilir. Semptomatik ve büyük intraabdominal kistler komplikasyon gelişmeden önce ameliyat edilmelidir.[20] Genellikle organ rezeksiyonu yapılmadan kistin tamamının çıkarılması uygundur.[21] Bu çalısmada sarılık ve mide agrıs şikayetiyle gelen 2 hasta koledok basısı ve kolelithiazis olması nedeniyle kolesistektomi+total perikistektomi yapıldı. Diğer 5 
vakada dalak hilus ile ilişkili olduğundan organ rezeksiyonuyla yapıldı. Çalısmada tüm hastalarda total perikistektomi yapıldığından takiplerinde nüks olmadığı saptandı.

\section{Sonuç}

Batın içi kitlelerde özellikle endemik bölgelerde Ekstrahepatik primer intraabdominal hidatik kist akla getirilmelidir. Hastalık tablosu çoğunlukla sessiz olmasına rağmen, kistin enfekte olması, karın boşluğuna rüptür, gastrointestinal sisteme fistülizasyon ya da perforasyon gibi komplikasyonlar gelişebilmektedir.Bu yüzden tedavide nüksü tamamen ortadan kaldıran total perikistektomi veya organ rezeksiyonuyla beraber total perikistektomi yapılmasını önermekteyiz.

\section{Çıkar çatışması/finansal destek beyanı}

Bu yazıdaki hiçbir yazarın herhangi bir çıkar çatışması yoktur. Yazının herhangi bir finansal desteği yoktur.

\section{Kaynaklar}

1. Kaymaz A, Hidatik Kist: Epidemiyoloji, Bulaşma ve Korunma Yolları. Hepato-Bilier Sistem ve Pankreas Hastalıkları Sempozyum Dizisi 2002; 28: 285-99.

2. Petrone L, Cuzzi G, Colace L et al. Cystic Echinococcosis in a Single Tertiary Care Center in Rome, Italy. Biomed Res Int 2013; 2013: 978146

3. Durgun V, Kapan S, KapanM et al. Primary splenic hydatidosis. Dig Surg 2003; 20: 38-41.

4. Mourglia-Ettlin G, Marqus JM et al. Early peritoneal immune response during Echinococcus granulosus establishment displays a biphasic behavior. PLoS Negl Trop Dis 2011; 5: 1293.

5. Burgos R, Varela A, Castedo E et al. Pulmonary hydatidosis: surgical treatment and follow-up of 240 cases. Eur J Cardiothorac Surg 1999; 16: 628-35

6. Yetim I, Erzurumlu K, Karaciğer Hidatik Kistleri Tedavisinde Güncel Yaklaşımlar. J Clin Anal Med 2013; 4: 64-71

7. Ammann RW, Eckert J. Cestodes Echinococcus. Gastroenterol Clin Nort Am 1996; 25: 655-89.
8. Aytac A, Yurdakul Y, İkizler C. Pulmonary hydatid disease: report of 100 patients. Ann Thorac Surg 1997; 23: 145- 51.

9. Kushwaha JK, Sonkar AA, Verma AK et al. Primary disseminated extrahepatic abdominal hydatid cyst: a rare disease BMJ Case Reports 2012; 30; 2012.

10. Merdivenci A, Aydınlıoğlu K. Hidatidoz (Hidatik Kist Hastalığı) 1982. İst. Üniv Tıp Fak. Yay. No:2972:97.

11. Wani RA, Malik AA, Chowdri NA et al. Primary extrahepatic abdominal hydatidosis. Int J Surg 2005; 3: 125-7

12. Yazı ı P, Aydın Ü, Ersin S et al. Dalak Yerlesimli Kist Hidatik: Klinik Çalısma. The Eurasian Journal of Medicine 2007; 39: 25-7.

13. Sekmenli T, Koplay M, Sezgin A, Isolated omental hydatid cyst: clinical, radiologic, and pathologic findings. J Pediatr Surg 2009; 44: $1041-3$

14. Kulaçoğlu HI , Oruç MT, Kocaerkek Z et al.Unusual locations of hydatid disease: an evaluation of 77 cases. Turk J Gastroenterol 2001; $12: 299-302$

15. Grossi G, Lastilla MG, Teggi A. 420 patients with hydatid cyst: Observations on the clinical picture. Arch Hidatid 1991; 30: 1021.

16. Pişkin T, Ara C, Dirican A et al. Ürtikerle belirti veren periton içine rupture kist hidatik olgusu. Dicle Tıp Derg 2010; 37: 71-4.

17. Aksoy Ü, İnci A. Kistik ekinokokozisin serolojik tanısında in-house enzim immün yöntemi ve indirekt hemaglütinason yönteminin kullanılması. Mikrobiyol Bül 2004; 38: 245-51.

18. Ormeci N. Diagnosis in hydatid disease. Turk Klin J Surg 1998; 3: $187-8$.

19. Ilica AT, Kocaoglu M, Zeybek $\mathrm{N}$ et al. Extrahepatic abdominal hydatid disease caused by Echinococcus granulosus: imaging findings. AJR Am J Roentgenol 2007; 189: 337-43

20. Köksal AF, Arhan M, Oğuz D. Kist Hidatik. Güncel Gastroenteroloji 2004; 8: 1.

21. Prousalidis J, Tzardinoglou K, Sgouradis L et al. Uncommon sites of hydatid disease. World J Surg 1998; 22: 17-22 